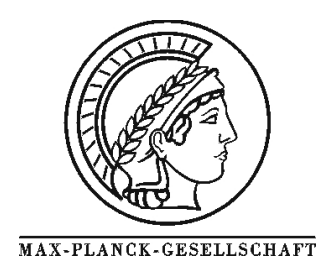

\title{
Pt/CERIA THIN FILM MODEL CATALYSTS AFTER HIGH TEMPERATURE REDUCTION: A (HR)TEM STUDY
}

\author{
S. Penner ${ }^{1 *}$ G. Rupprechter ${ }^{2}$, H. Sauer ${ }^{2}$, D. S. Su ${ }^{2}$, R. Tessadri ${ }^{3}$, R. Podloucky ${ }^{4}$, \\ R. Schlögl ${ }^{2}$, K. Hayek ${ }^{1}$ \\ ${ }^{1}$ Department of Inorganic Chemistry, Fritz-Haber-Institute of the MPG, Faradayweg 4-6, 14195 Berlin, Germany \\ ${ }^{2}$ Fritz-Haber Institut der Max-Planck-Gesellschaft, Faradayweg 4-6, D-14195 Berlin, Germany \\ ${ }^{3}$ Institut für Mineralogie und Petrographie, Leopold-Franzens-Universität, A-6020 Innsbruck, Austria \\ ${ }^{4}$ Center for Computational Materials Science \& Universität Wien, Liechtensteinstr. 45, A-1090 Vienna, Austria \\ * Corresponding author: e-mail simon.penner@uibk.ac.at, phone +43 512507 5066, +43 5125072925
}

Received 16 June 2002; accepted 24 September 2002

\begin{abstract}
Well-facetted Pt particles, epitaxially grown on (001) $\mathrm{NaCl}$ single crystal surfaces, were supported by thin films of crystalline ceria. Structural and morphological changes due to calcination and reduction have been studied after treating in oxygen $(673 \mathrm{~K}, 1 \mathrm{~h})$ and hydrogen exposure at increasing temperatures from 673 to $1073 \mathrm{~K}$. These changes were followed by (HR)TEM, electron diffraction and EELS, and possible structures were selected with help of density functional calculations. Reduction at 723K causes the transformation of the initially half octahedral Pt particles into cube or platelet shapes with a double lattice periodicity in both HRTEM image and electron diffraction pattern. This can be attributed to the hydrogen-influenced topotactic formation of a $\mathrm{Pt}_{3} \mathrm{Ce}$ alloy phase of high thermodynamic stability as confirmed by DFT calculations. Further heating of the ceria-based catalyst in hydrogen up to $1073 \mathrm{~K}$ results in clustering of metal particles on large flat areas of the sintered support with lattice periodicities between 0.8 and $1.2 \mathrm{~nm}$. EELS and X-ray diffraction both confirm partial reduction of ceria and indicate the formation of chemically stable Ce suboxides.
\end{abstract}

Keywords: Platinum, ceria, electron microscopy, alloy formation, hydrogen reduction, surface reconstruction

\section{Introduction}

Ceria supported noble metals are widely used as valuable catalysts in deNOx and combustion

technology. However, like most noble metal-reducible oxide combinations they are subjected to strong metal-support interaction upon high temperature reduction, resulting in a change of structure, catalytic properties [1] and eventually deactivation. Investigation of these phenomena is greatly facilitated by the properties of the studied thin film model catalysts: They are characterised by a narrow size distribution and defined particle shapes and well suited for plan view lattice imaging by HRTEM [2]. As SMSI-like behaviour usually starts to develop under hydrogen treatment at elevated temperatures, the present work focuses on the changes in both structure and morphology of ceria-supported $\mathrm{Pt}$ particles subjected to varying reduction procedures in the temperature range between $673 \mathrm{~K}$ and $1073 \mathrm{~K}$. The results are compared to experiments on "non-SMSI" systems (especially Pt/silica and Pt/alumina), where similar observations were made under identical experimental conditions [3]. (HR)TEM, electron diffraction and EELS were used to monitor the resulting changes and assisted by density functional calculations performed with the VASP code.

\section{Experimental}

Pt particles were deposited by electron-beam evaporation at $623 \mathrm{~K}$ on a fresh vacuum-cleaved $\mathrm{NaCl}(001)$ single crystal surface. Subsequently, they were covered by a layer of crys- 
talline ceria $(\sim 25 \mathrm{~nm})$. Ceria was prepared by thermal evaporation of $\mathrm{CeOx}$ in 10-5 mbar oxygen. The resulting thin films were put into distilled water in order to remove the $\mathrm{NaCl}$, dried and finally mounted on gold grids for electron microscopy. After an oxidising treatment $\left(1\right.$ bar $\mathrm{O}_{2}$, $673 \mathrm{~K}, 1 \mathrm{~h})$, the films were exposed to hydrogen at varying temperatures up to $1073 \mathrm{~K}$ for one hour, either in a flow system or a circulating batch reactor. Their morphology and structure were examined by HRTEM and EELS and compared to the as-grown state. The images were taken with a Zeiss EM 10C, a Philips CM 200 FEG and a JEOL 4000 microscope. EELS measurements were performed at the Philips CM 200 FEG equipped with a Gatan energy filter.

\section{Results and Discussion}

The as-grown state of the ceria-supported Pt particles is shown in Fig 1: In this low-magnification TEM image the Pt particles (mean diameter: $10 \mathrm{~nm}$ ) can be identified as dark and grey spots of square or rectangular shape, the black ones being aligned in perfect Bragg orientation, the latter more or less tilted out of the respective Bragg position. Weak-beam dark field images of the corresponding alumina-based catalysts reveal the half-octahedral habit of most metal particles [2]. Their almost perfect orientation with respect to the original $\mathrm{NaCl}$ substrate is confirmed by the SAED pattern (insert a). HRTEM images of octahedral particles show (200) lattice fringes of the Pt fcc structure $\left(\mathrm{d}_{200}(\mathrm{Pt})=1.96 \AA\right)$, including an angle of $45^{\circ}$ with the particle edges (attachment b). Thus, most of the Pt particles exhibit (001) base planes perpendicular to the electron beam. They are surrounded by grains of fluorite type ceria. The SAED patterns reveal a partial epitaxial correlation between Pt particles and ceria, but most ceria grains are not well oriented with respect to each other. Ceria exhibits mainly (111) lattice fringes in HRTEM images $\left(\mathrm{d}_{111}(\right.$ ceria $\left.)=3.12 \AA\right)$.

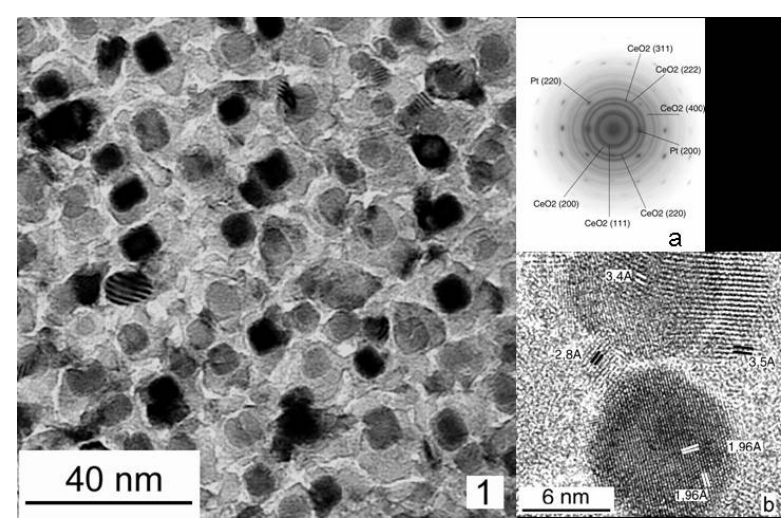

Fig. 1: As-grown Pt particles supported by crystalline ceria. Attachments: selected area electron diffraction (SAED) pattern (a) and HRTEM image of a half-octahedral Pt particle (b).

Low-temperature reduction ( 1 bar $\mathrm{H}_{2}, \mathrm{~T} \leq 723 \mathrm{~K}, 1 \mathrm{~h}$ ) leads to a slight sintering of the ceria support (as indicated by the closing of the grain boundaries) and to the appearance of higher-indexed facets on the metal particles, generally explained in terms of a hydrogen-induced equilibrium shape. However, after reduction at $723 \mathrm{~K}$ these particles are transformed into a new cube or platelet like structure. Their cube shape is compatible with the absence of the characteristic contour lines in weak-beam dark field images of silica supported Pt particles under similar reduction conditions [3]. Fig. 2 shows that the recrystallised particles are still well

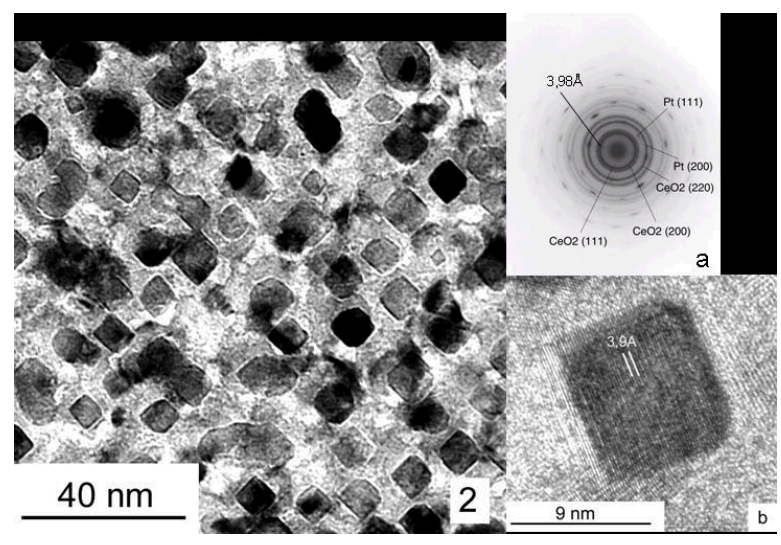

Fig. 2: Pt particles supported by ceria after hydrogen reduction at $723 \mathrm{~K}$ for one hour. Attachments: corresponding SAED pattern (a) and HRTEM image of a recrystallised particle (b).

oriented to each other and probably pinned to the former steps of the $\mathrm{NaCl}$ substrate. The corresponding SAED pattern (attachment a) reveal also Pt (111) reflections indicating a change of metal-support interface of some particles. Nevertheless, most of the particles keep in [001] zone, changing only their azimuthal orientation. At $\mathrm{d}=3.98 \pm 0.1 \AA$ four additional distinct spots coinciding with the forbidden (100) reflection of fcc Pt are detected. Similar periodicities are also found in HRTEM images (attachment b), revealing the corresponding lattice fringes as parallel to the particle edges. This "doubling of the Pt (200) distance" $\left(2 \times \mathrm{d}_{200}(\mathrm{Pt})=\right.$ $3.92 \AA$ ) might be explained by a particle reconstruction under hydrogen, but recent studies on the corresponding silica and alumina based catalysts proved the formation of a $\mathrm{Pt}_{3} \mathrm{Me}$ $(\mathrm{Me}=\mathrm{Si}, \mathrm{Al})$ alloy phase of simple cubic $\mathrm{Cu}_{3} \mathrm{Au}$ structure with a lattice constant only slightly differing from the $\mathrm{Pt}$ value $\left(\mathrm{a}(\mathrm{Pt})=3.92 \AA, \mathrm{a}\left(\mathrm{Pt}_{3} \mathrm{Si}\right)=3.89 \AA\right.$ and $\mathrm{a}\left(\mathrm{Pt}_{3} \mathrm{Al}\right)=$ 3.87 $\AA$ ) [3]. A bulk $\mathrm{Pt}_{3} \mathrm{Me}$ phase is also known for the $\mathrm{Pt} / \mathrm{Ce}$ system [4], with a lattice constant of $4.16 \AA$ slightly larger than that of $\mathrm{Pt}_{3} \mathrm{Si}$ and $\mathrm{Pt}_{3} \mathrm{Al}$. Further weak reflections in the SAED pattern can also be attributed to this $\mathrm{Pt}_{3} \mathrm{Ce}$ phase (see Table 1) while most other possible PtCe alloys [5,6] can be excluded. The new cube-like structure persists up to reduction in hydrogen at $973 \mathrm{~K}$.

As the observations on $\mathrm{Pt} /$ ceria are very similar to those on

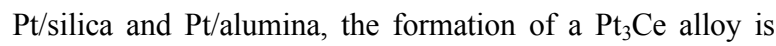
considered most likely to occur under the given experimental conditions. The formation of sharp-edged particles upon high-temperature reduction of (silica) supported Pt particles has been reported previously $[7,8]$ and has been explained 
by a surface reconstruction under the influence of hydrogen, leading the system to a minimum surface energy [8]. However, alloy formation has also been reported, e.g. $\mathrm{Pt}_{3} \mathrm{Si}$ by Lamber et al. [10] and $\mathrm{Pt}_{5} \mathrm{Ce}$, with larger lattice parameters, by Bernal et al. [5] and Abid et al. [11] on Pt/ceria. In addi-

Table 1: Experimentally measured interplanar distances $d_{\mathrm{hkl}}$ $[\AA]$ and their assignment

\begin{tabular}{|c|c|}
\hline $\begin{array}{l}\text { Experimental } d_{h k l} \\
\text { of } \mathrm{Pt}_{x} \mathrm{Ce}_{\mathrm{y}}[\AA]\end{array}$ & Assignment \\
\hline 3.98 & $\mathrm{Pt}_{3} \mathrm{Ce}(100)$ \\
\hline 3.17 & $\mathrm{CeO}_{2}(111)$ \\
\hline 2.95 & $\mathrm{Pt}_{3} \mathrm{Ce}(110)$ \\
\hline 2.74 & $\mathrm{CeO}_{2}(200)$ \\
\hline 2.41 & $\mathrm{Pt}_{3} \mathrm{Ce}(111)$ \\
\hline 2.23 & $\mathrm{Pt}(111)$ \\
\hline 2.10 & $\mathrm{Pt}_{3} \mathrm{Ce}(200)$ \\
\hline 1.95 & $\begin{array}{l}\mathrm{Pt}(111) \text { and } \\
\mathrm{CeO}_{2}(220)\end{array}$ \\
\hline 1.67 & $\mathrm{CeO}_{2}(311)$ \\
\hline 1.57 & $\mathrm{CeO}_{2}(222)$ \\
\hline 1.49 & $\mathrm{Pt}_{3} \mathrm{Ce}(220)$ \\
\hline 1.37 & $\begin{array}{l}\mathrm{Pt}(220) \text { and } \\
\mathrm{CeO}_{2}(400)\end{array}$ \\
\hline
\end{tabular}

tion, density functional calculations using the VASP code [12] show a remarkable stability of the $\mathrm{Pt}_{3} \mathrm{Ce}$ phase compared to $\mathrm{Pt}_{3} \mathrm{Si}$ and $\mathrm{Pt}_{3} \mathrm{Al}$ (Table 2). We have previously explained the formation of $\mathrm{Pt}_{3} \mathrm{Si}$ and $\mathrm{Pt}_{3} \mathrm{Al}$ alloy phases upon

Table 2: VASP calculated formation energies $[\mathrm{eV}]$ of different $\mathrm{Pt}_{3} \mathrm{Me}$ compounds

\begin{tabular}{|l|l|l|}
\hline Phase & $\mathbf{E}_{\text {form }}[\mathbf{e V}]$ & $\mathbf{E}_{\text {form }}$ per atom $[\mathbf{e V}]$ \\
\hline $\mathbf{P t}_{\mathbf{3}} \mathbf{C e}$ & -3.888 & -0.972 \\
\hline $\mathbf{P t} \mathbf{3} \mathbf{S i}$ & -1.201 & -0.300 \\
\hline $\mathbf{P t}_{\mathbf{3}} \mathbf{A l}$ & -2.754 & -0.689 \\
\hline
\end{tabular}

high-temperature reduction by a surface reconstruction of the Pt particles under hydrogen followed by topotactic growth of the alloy at the metal-support interface. On $\mathrm{Pt} /$ ceria the alloying process starts at slightly lower temperature $(723 \mathrm{~K})$ than on $\mathrm{Pt} /$ silica and $\mathrm{Pt} /$ alumina $(\mathrm{T} \geq 773 \mathrm{~K})$ which may be explained by the better epitaxy of crystalline ceria and $\mathrm{Pt}$, facilitating the topotactic growth of the alloy in the proper structure and orientation. The observed disagreement between the experimentally determined lattice constant (HRTEM 3.9 $\AA$, electron diffraction $3.98 \AA$ ) and the expected bulk value of $\mathrm{Pt}_{3} \mathrm{Ce}(4.16 \AA)$ could be due to the fact that at this growth stage the incorporation of $\mathrm{Ce}$ into the former Pt lattice is not yet completed. It must be pointed out that the probability of formation of a specific alloy and the onset temperature of formation will depend on the experimental conditions (contact area between metal and oxide, crystallinity of the oxide, possibility of topotactic growth etc.) which may also explain the different results obtained by other authors $[5,6,13,14]$.

Further heating of the $\mathrm{Pt} /$ ceria catalyst in hydrogen at $1073 \mathrm{~K}$ leads again to a different picture. Clustering of metal particles is observed together with a structural change of the ceria support. Widespread periodic patterns with lattice periodicities between about 4 and $12 \AA$ appear on large flat areas of partly reduced, sintered ceria (Fig. 3). HRTEM images (attachment a) reveal that the larger lattice fringes are often three- or fourfold subdivided. The corresponding

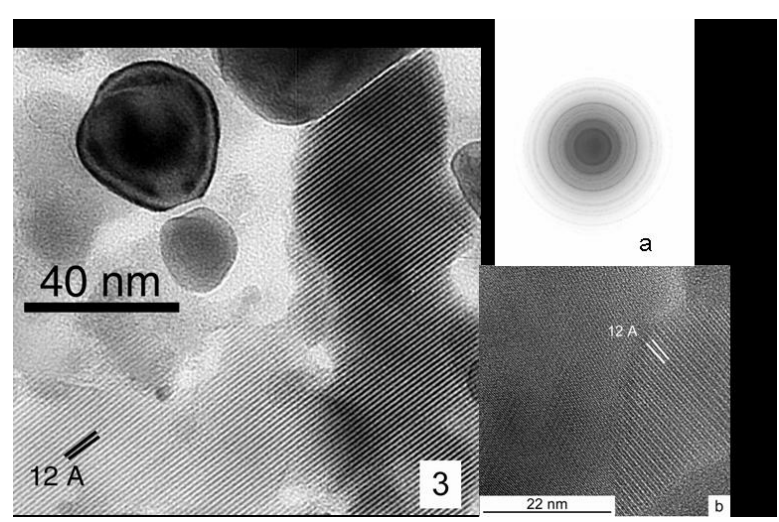

Fig. 3: The $\mathrm{Pt} /$ ceria thin film after hydrogen reduction at 1073K for one hour. Attachments: SAED pattern (a) and HRTEM image (b).

electron diffraction patterns (attachment b) show series of additional sharp rings, although it is still possible to detect $\mathrm{Pt}$ and fluorite-type $\mathrm{CeO}_{2}$. The same HRTEM images and diffraction patterns are also obtained upon reducing a bare ceria film. Similar patterns have been reported by Krause et al. [15] after high-temperature reduction of a Pt/ceria/silica system and attributed to the formation of cerium silicate $\left(\mathrm{Ce}_{2} \mathrm{Si}_{2} \mathrm{O}_{7}\right)$, but the presence of $\mathrm{Si}$ could be excluded by EELS in the present case. Furthermore, X-ray diffraction of thicker ceria films after high-temperature reduction shows an overall decrease of diffracted intensities from fluorite type ceria and the appearance of new reflections which arise very likely from reduced ceria phases. On the other hand, 
EELS measurements on the reduced ceria support reveal that the structural change is accompanied by a change of the oxidation state from $\mathrm{Ce}^{4+}$ to $\mathrm{Ce}^{3+}$, so that most likely a defect superstructure with a distorted fluorite lattice is formed. $\mathrm{CeO}_{2}$ is very-well known to form a large number of substoichiometric phases $\mathrm{CeO}_{\mathrm{x}}(1.714 \leq \mathrm{x} \leq 2)$ upon hightemperature reduction, most being characterised by an ordering of the formed oxygen vacancies and a fluorite-related lattice [16]. Although most of these structures are reported to be easily reoxidised under atmospheric conditions their kinetic stability may be enhanced by a surrounding thin layer of cerium hydroxide. Density functional calculations and additional EELS measurements are presently carried out in order to determine the possible atomic arrangement in this superstructure, but of course in-situ experiments will also be needed to prevent reoxidation under ambient conditions.

\section{Conclusions}

After reduction of a Pt/ceria thin film catalyst SAED analy-

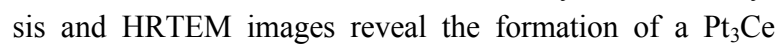
alloy compound crystallising in the simple cubic $\mathrm{Cu}_{3} \mathrm{Au}$ structure. After reduction at $1073 \mathrm{~K}$ striking structural changes of the ceria support occur and enable the Pt particles to coalesce to large aggregates. These changes are most likely due to a bulk reduction of ceria and the formation of a defect superstructure, exhibiting the observed lattice periodicities. Presently, VASP calculations and EELS measurements are carried out in order to determine the origin of this defect structure.

\section{Acknowledgement}

Part of this work was supported by the Austrian Science Fund (Projects S 8105 and S 8106).

\section{References}

[1] Trovarelli A. Catal. Rev.-Sci. Eng. 1996;38:439

[2] Rupprechter G, Hayek K, Rendón L, José-Yacamán M. Thin Solid Films 1995;260: 148

[3] Penner S, Wang D, Su D S, Rupprechter G, Podloucky R, Schlögl R, Hayek K.

Surf. Sci., submitted

[4] Landolt-Börnstein, New Series III/6, Structure Data of Elements and Intermetallic Phases, Springer, Berlin 1971.

[5] Chojnacki T, Krause K, Schmidt L D. J. Catal. 1991;128:161.

[6] Bernal S, Calvino J J, Gatica J M, Larese C, Lopez-Cartes C, Pérez-Omil J A.

J. Catal. 1997;169:510.

[7] Wang T, Lee C, Schmidt L D. Surf. Sci. 1985;163:181

[8] Romanowski W, Lamber R. Thin Solid Films 1985;127:139

[9] Shi A C, Masel R I. J. Catal. 1989;120:421

[10] Lamber R, Jaeger N. J. Appl. Phys. 1991;70:457

[11] Abid M, Ehret G, Touroude R. Appl. Catal. A 2001;217:219-229

[12] Kresse G, Hafner J. Phys. Rev. B 1993;B47:RC 558

[13] Schwartz J M, Schmidt L J. J. Catal. 1992;138: 283.

[14] Hardacre C, Roe G M, Lambert R J. Surface Sci. 1995;326:1.

[15] Krause K R, Schabes-Retchkiman P, Schmidt D L. J. Catal. 1992;134:204.

[16] Trovarelli A, Catalysis by Ceria and Related Materials, A. Trovarelli Ed., Catalytic Science Series Vol. 2, Imperial College Press 2002, p. $15 \mathrm{ff}$. 